\title{
TESTIMONIOS DE LA PEDAGOGÍA DE LAS CONDUCTAS MOTRICES APLICADA CON EL MÉTODO MOVITRANSFER
}

\author{
EVIDENCES OF THE MOTOR BEHAVIOR PEDAGOGY APPLIED WITH MOVITRANSFER \\ METHOD
}

Bernardo Masciano ${ }^{1}$ Alberto José Masciano ${ }^{2}$ Francisco Lagardera ${ }^{3}$

\section{Resumen}

\begin{abstract}
Al aplicar la pedagogía de las conductas motrices se produce, de manera ineludible, un cambio de paradigma en educación física, dado que otorgar el protagonismo del proceso educativo a la conducta motriz implica, necesariamente, que el foco de atención del docente se centre en cada una de las personas que aprenden. En el Gimnasio Olimpia, de la ciudad argentina de Chivilcoy, se está llevando a cabo, de un modo eficaz y exitoso, esta importante y necesaria transformación. Las clases de educación física que allí se imparten se llevan a cabo mediante un método singular e innovador, que aplica la pedagogía de las conductas motrices con propuestas pedagógicas basadas en procesos de exploración motriz, generando dinámicas pedagógicas mediante puestas en común y circuitos con situaciones psicomotrices y sociomotrices. Este artículo muestra los resultados de una investigación cualitativa realizada entre una muestra significativa de personas que asisten al gimnasio, y que han dejado sus testimonios contestando a la pregunta: ¿Qué aprendes en las clases de Movitransfer?
\end{abstract}

Palabras clave: conducta motriz, pedagogía de las conductas motrices, exploración motriz, método Movitransfer

\section{Abstract}

When applying the motor behavior pedagogy, it occurs, inescapably, a paradigm shift in physical education, since granting the role of education in motor behavior process necessarily implies that teacher focuses on each one of the learners. In Gimnasio Olympia, at Chivilcoy village, Argentina, this important and necessary transformation is being carried out effectively and successfully. The physical education classes taught there are conducted through a unique and innovative method, applying the motor behavior pedagogy with processes of motor exploration, generating pedagogical proposals by sharings and circuits with psychomotor and socio-motor situations. This article shows the results of a qualitative research conducted with a significant sample of people who attend the institution and have contributed with their testimonies answering the question: What do you learn in Movitransfer classes?

Keywords: motor behavior, motor behavior pedagogy, motor exploration, Movitransfer method

Fecha de recepción: 4 de diciembre de 2015

Fecha de aprobación: 6 de mayo de 2016

Para citar este artículo:

Masciano, B., Masciano, J. A. \& Lagardera, F. (2016). Testimonios de la pedagogía de las conductas motrices aplicada con el método Movitransfer. Lúdica Pedagógica, 24, 95-105.

1 Magíster en Educación Física, Instituto Superior Enrique Romero Brest, INEF № 1, Buenos Aires, Argentina. Profesor nacional de educación física, Instituto Superior Enrique Romero Brest, INEF N 1, Buenos Aires, Argentina. Licenciado en actividad física y deporte, UFLO, Buenos Aires, Argentina. Posgrado en coaching, Institut Integratiu, de Barcelona, España. Entrenador personal en training BCN.es, Barcelona, España. Secretario de la FIEP para Cataluña. Correo electrónico: bmasciano@gmail.com

2 Profesor, Universidad de Flores (UFLO), Facultad de Actividad Física y Deporte, Buenos Aires, Argentina. Profesor Nacional de Educación Física, Instituto de Educación Física General Belgrano, de Buenos Aires, Argentina. Director, Gimnasio Olimpia, de Chivilcoy, Argentina. Correo electrónico: albertomasciano@hotmail.com

3 Doctor en Filosofía y ciencias de la educación, Universidad de Barcelona, España. Licenciado en historia contemporánea, Universidad de Barcelona, España. Licenciado en educación física, Universidad de Barcelona, España. Graduado en pedagogía — profesor de enseñanza general básicaUniversidad de Madrid, España. Catedrático de sociología del deporte — jubilado— INEFC, Universidad de Lleida, España. Correo electrónico: pacolagardera@gmail.com 


\section{INTRODUCCIÓN}

Los seres humanos al nacer aparecen en el mundo con un repertorio motor sumamente rico, producto de la evolución filogenética de la especie, que se madura a lo largo de los primeros tres años de vida, pero, sorprendentemente, este gran capital de la motricidad parece reducirse con el transcurrir del tiempo.

Cualquiera que pueda tener a un bebé entre sus brazos podrá vivir la bella experiencia de sentir su apacible y rítmica respiración diafragmática. Pero millones de personas adultas tienen grandes dificultades para mantener una respiración profunda como lo hace un bebé recién nacido. Lo mismo ocurre con los estiramientos espontáneos y naturales que llevan a cabo los bebés cuando se despiertan estando sanos, satisfechos y limpios; y al igual que los cachorros de gatos y perros a los cuales nadie ha enseñado a estirarse, pero, a diferencia de los humanos, siguen estirándose de adultos. Así mismo, un niño de tres años es capaz de adoptar una postura sedente sobre una silla de su medida, de un modo justo y equilibrado, manteniendo la espalda alineada y estirada. Actitud muy extraña en una persona adulta.

El soporte de las facultades operatorias humanas se encuentra en la motricidad inteligente (Parlebas, 2001) que empuja a la exploración del mundo en los primeros tres años de vida. Pero el proceso de indagación y exploración motriz (Feldenkrais, 1988) no puede detenerse después de los tres años, pues se necesita explorar e indagar la sabiduría filogenética de la especie, grabada en todas las células, y que espera ser activada por la luz de la conciencia.

A esta tarea dedica el método Movitransfer la primera parte de las sesiones de educación física, con el fin de que las personas, siguiendo cada cual su propio proceso, sean capaces de redescubrir este maravilloso y rico legado a través de una situación motriz conocida como desanudarse (Lagardera \& Masciano, 2011b). Un modo práctico y eficaz de centrarse y conectarse, de manera consciente y sensitiva, con el estado del cuerpo en cada momento del presente.

\section{UN NUEVO PARADIGMA PARA LA EDUCACIÓN FÍSICA}

La educación física actual sigue haciendo referencia constante al paradigma basado en el movimiento humano, desde el cual lo que importa es la acción motriz que se va a reproducir. Con esta perspectiva, no son las personas con sus singularidades lo que interesa al pedagogo, sino el modo como se realiza la tarea motriz en unos casos, o, simplemente, el resultado que es capaz de alcanzar cada persona en su reproducción.

Esta situación se explica y se mantiene porque en la cultura hegemónica actual, tanto deportiva como económica y social, se valora más y mejor a quien corre más rápido, a quien lanza más lejos la bola o a quien salta más alto, como también se toman en cuenta dichas variables para determinar quién es "más competente" en educación física. Pero en este ámbito es factible aplicar, con relativa sencillez, otro modo de obrar pedagógico mucho más humano, centrado en la persona que aprende.

La persona, con sus características singulares y únicas, sigue siendo el punto ciego o el lado oculto de la educación física (Lagardera \& Masciano, 2014). Por más esfuerzos que han hecho multitud de autores para centrar la educación física en la persona, esta disciplina pedagógica sigue aferrada a las habilidades y las destrezas que conforman sus objetivos, al margen de los rasgos y las necesidades de cada ser humano.

Cualquier persona se comunica, se expresa y se relaciona a través de su propia motricidad, de un modo singular y único, ya que estos modos de obrar siempre se manifiestan de manera global y unitaria mediante conductas motrices (Parlebas, 2001). Aunque últimamente estos modos de obrar se disfracen como competencias. ¿Acaso existe una competencia procedimental más útil que la que optimiza la conducta motriz orientada en la dirección de los propios intereses y las necesidades de cada persona? (Masciano, Masciano \& Lagardera, 2013).

El método Movitransfer ha tomado el concepto de conducta motriz y lo ha aplicado en la dinámica de sus clases de educación física, de un modo cotidiano y eficaz (Lagardera \& Masciano, 2011a), y así ha logrado iluminar ese lado oculto de la educación física, observando de modo constante y sistemático los comportamientos motores de sus alumnos y las emociones que los alientan, y conociendo la biografía de cada cual, interpretando de manera global todos esos indicadores como conductas motrices. De esta manera, ha logrado levantar el telón que cubría la singularidad de cada persona y tratar a cada cual según sus necesidades (Masciano \& Lagardera, 2012). 
La aplicación de la pedagogía de las conductas motrices (Lagardera \& Lavega, 2005) en el Gimnasio Olimpia, de la ciudad de Chivilcoy, en la provincia de Buenos Aires, ha supuesto la reorientación de la educación física en varias direcciones:

a. En la focalización del centro de interés pedagógico, que se traslada a la persona con sus singularidades, sean cuales sean la edad, el género, la condición física y cualquier otra, lo cual supone que se pueda acoger en una misma clase a personas muy diferentes: a una anciana, a alguien con dificultades motoras y también, a deportistas que compiten habitualmente a buen nivel (Lagardera \& Masciano, 2014).

b. En el papel del docente, que ya no es el de quien lo sabe hacer todo y quien describe la competencia eficaz y única por lograr, sino que se convierte en aprendiz del alumnado, de quienes cada día va descubriendo nuevos modos de hacer, en observador constante de su comportamiento motor y en un sagaz intérprete de sus conductas motrices (Masciano \& Lagardera, 2012).

c. En la necesidad de iniciar las clases de educación física a través de un proceso íntimo y singular de introyección motriz (Lagardera, 2007b), conocido como desanudarse, y en el que cada cual recupera de su olvidado repertorio motor conductas motrices adecuadas y eficaces para su estado general en ese momento del día, antes de comenzar con las demás actividades de la clase, dado que cada persona necesita centrarse en sí misma, percibirse con claridad y relacionarse con mayor eficacia con los demás, con el espacio y con los recursos materiales (Masciano et al., 2013).

d. En el modo de evaluar y de evaluarse, pues la intervención del docente y la del alumnado en el discurrir de la clase, mediante puestas en común breves y sistemáticas, logran que las personas implicadas puedan ser conscientes, semana a semana, de los procesos de optimización de sus conductas motrices y de las consecuencias que tiene este proceso en el devenir de su vida cotidiana (Masciano \& Lagardera, 2011). e. Fomentando la motivación y el interés de los participantes en las clases mediante la organización de circuitos, tanto psicomotores como sociomotores, que al mantenerse durante varias semanas sirven de pauta referencial para cada participante, que siempre se ve aceptado e integrado en un grupo heterogéneo y diverso, el cual va cambiando en cada clase, lo que supone un proceso interactivo de gran impacto, pues, incluso cuando se trata de tareas psicomotrices, se forman grupos y equipos de trabajo (Masciano \& Lagardera, 2011).

\section{MÉTODO}

Esta investigación plantea un estudio de caso basado en un método de tipo fenomenológico, ya que no es sino preguntando a los propios protagonistas del proceso de transformación, a través de las clases de educación física proporcionadas por Movitransfer, como las personas pueden estar en condiciones de comunicar qué, cómo y de qué naturaleza son los cambios que se están produciendo en sus vidas (Masciano, 2013).

Se debe tener muy presente, en todo momento, que tanto para la pedagogía de las conductas motrices como para el método Movitransfer, la persona, cualesquiera que sean su edad, su género y su condición física, es el centro del proceso educativo. Con esta óptica, la persona protagonista de la acción es el informante básico para adentrarse en un trabajo de campo tratado como caso único e irrepetible.

La población objeto del estudio está formada por las personas inscritas en el Gimnasio Olimpia, de Chivilcoy, y la muestra es una distribución proporcional estratificada de afijación simple no aleatoria (García Ferrando, Ibáñez \& Alvira, 1992); ello quiere decir que sus estratos se hallan distribuidos y estipulados de antemano por cuotas delimitadas, a su vez, por diferentes criterios y características. A cada uno de los estratos de la muestra le corresponde un mismo número de entrevistas, pues se ha elegido un tipo de muestra de afijación simple, que busca una representación media por estratos, con el fin de que todos los segmentos de edad y de género estén representados (Masciano, 2013).

El universo de trabajo se ha estratificado de la siguiente manera: 
a. Jóvenes de 15 a 30 años; con 18 testimonios entregados en la fecha límite estipulada.

b. Adultos de 30 a 50 años; con 45 testimonios entregados en la fecha límite estipulada.

c. Mayores de más de 50 años; con 10 testimonios entregados en la fecha límite estipulada.

Tomando en cuenta el número mínimo de comentarios que se poseían a la fecha de entrega estipulada de antemano (especialmente, de la categoría de mayores, por disponer del menor número de ellos - en concreto, diez-), se estableció que la representación de diez personas por estrato era suficientemente representativa y fiable, a tenor de que este era el número mínimo de contestaciones del cual se disponía de cada estrato. Con los estratos en los que se disponía de más de diez testimonios, se procedió a escoger al azar entre el excedente de respuestas, hasta cuando quedó un número de diez testimonios para cada estrato; el total de la muestra fue de 30 testimonios.

El instrumento de recolección de datos fue el cuestionario abierto (Álvarez \& Jurgenson, 2003), lo que permite al investigador llegar a más cantidad de personas sin la necesidad de estar cara a cara con ellas, y así poder elaborar una pregunta, en este caso, que guarde una relación de congruencia con el problema por investigar; es decir, que las personas que participen del cuestionario puedan reflexionar y dar su opinión sobre el tema del cual se busca obtener información (Masciano, 2013).

La pregunta fue hecha en el Gimnasio Olimpia, lugar donde se desarrollan semana a semana las sesiones con el método Movitransfer, el 1 y el 2 de marzo del 2011, en todas las clases y los grupos, de lunes a jueves; se marcó como fecha límite para recoger los textos el viernes de esa misma semana, día en que los usuarios asisten libremente al gimnasio para llevar a cabo trabajos personales.

La pregunta fue apuntada en el pizarrón de la entrada del gimnasio, con una breve explicación sobre su finalidad, y formulada en los siguientes términos: ¿Qué crees haber aprendido desde que practicas con el método Movitransfer? No obstante, el proceso que se iba a seguir fue explicado con detenimiento al final de cada sesión ante todas las personas asistentes; se insistió en la necesidad de que se tratara de un testimonio anónimo, honesto y sincero.

\section{RESULTADOS}

A partir del análisis de contenido inductivo aplicado a los textos de los informantes, se construyeron cuatro grandes ejes temáticos, en torno a los cuales se han agrupado los textos seleccionados como más representativos y de mayor significación y relevancia.

\section{La vida cotidiana inspira el trabajo realizado en clase}

Las personas dicen ser capaces de optimizar sus conductas motrices para aplicarlas en la vida cotidiana a partir de la práctica y el entrenamiento de estas en el gimnasio. Comentan que el proceso seguido consiste en poner el cuerpo en la mejor disponibilidad posible para actuar de la forma más eficaz en las diferentes situaciones motrices que exige la vida: "El cuerpo destinatario activo logra mejoras ineludibles en su contacto con la diaria realidad de sus avatares" (informante 26). Es decir, cada persona experimenta en el gimnasio aprendizajes dirigidos a optimizar sus conductas motrices, que luego puede transferir a las situaciones de la vida diaria: "Todo lo aprendido nos sirve para la vida, todo lo que aprendemos en el Gim es inconscientemente adaptado a lo cotidiano, es aprender día a día algo nuevo, una experiencia inexplicable" (informante 9).

De esta práctica motriz, que forma parte de la vida misma, cada persona consigue una singular y progresiva evolución de sus conductas motrices que le permiten llevar a cabo prestaciones cada vez más eficientes en las distintas tareas cotidianas, actuando con mayor armonía, fluidez y naturalidad, por lo cual la mejora para toda persona que practica asiduamente con el método se refleja en casi todas las acciones motrices de su vida cotidiana.

Aprendí a usar el cuerpo en lo cotidiano, en la vida misma, sacándole ventajas a su uso consciente economizando esfuerzos. Los movimientos enseñados y aprendidos los pude transferir a la vida, esto me permite saber caminar elegante, observar el entorno, estar atento, saber cómo estar parado en una cola, como estar sentado por un largo tiempo, qué hacer al tropezar en una vereda o al doblar el tobillo por un desnivel (informante 17).

Este informante, quien experimenta activamente las clases de Movitransfer, describe algunas situaciones que están dentro de la definición de lo cotidiano, situaciones comunes que todas las personas experimentan día a 
día, y las cuales, con la práctica asidua del método, se transforman en conductas motrices conscientes que se realizan con mayor fluidez y economía de esfuerzo.

Especialmente expresiva es la descripción que detalla la naturaleza motriz de su transformación desde cuando se empieza a practicar con el método Movitransfer: "En lo cotidiano me desenvolvía con torpeza chocándome con cosas y gente, tropezándome, tirando objetos involuntariamente, mientras que tras comenzar a practicar el método, suprimí este manejo ilógico y lo reemplacé por uno más cuidadoso e incluso más espontáneo" (informante 4).

Dentro del ámbito de lo cotidiano, cobra especial importancia todo cuanto tiene que ver con el trabajo, lo que demanda gran parte del tiempo diario y de la energía vital; personas que llevan a cabo trabajos muy distintos: empleados de la banca, dentistas, maestras, psicólogas, arquitectos, taxistas, comerciantes, médicos...

Todas estas personas realizan tareas en las que su cuerpo, en mayor o menor medida, está implicado, e, incluso, es, o puede ser, el protagonista principal: sentarse y levantarse de una silla, caminar, elevar o transportar un peso, girarse cuando alguien llama, y muchas más situaciones cotidianas que son practicadas de un modo sistemático y consciente en todas las situaciones motrices propuestas por Movitransfer, y en las clases. "Gran utilidad en el trabajo y en la vida cotidiana donde hay que interactuar con muchas cosas a la vez y hay que tomar decisiones permanentemente" (informante 13).

Explorando y redescubriendo su propia motricidad de origen, las personas obtienen mayor calidad de vida, mejoran no solo en el trabajo, sino en todas las situaciones de la vida. Las personas dedicadas a la práctica deportiva, en cualquiera de sus ámbitos y sus niveles, también mejoran en la observación de las situaciones de juego, en la toma de decisiones estratégicas y en cuanto a optimizar conductas motrices en relación con la lógica interna de la modalidad deportiva de que se trate: "Pude conocer tres principios fundamentales para el deporte pero que también pueden aplicarse efectivamente a la vida cotidiana: observar, elegir, decidir" (informante 2); o este otro, mucho más explícito, si cabe: "Siento haber logrado transferir las conductas motrices a las situaciones de la vida y al deporte" (informante 6). No importa el deporte que practique cada persona, ni el tipo de acciones motrices que la vida diaria les exija realizar, pues el trabajo sistemático y consciente que se lleva a cabo en clase incide directamente sobre la evolución singular de las conductas motrices de cada una de las personas implicadas en las sesiones ofrecidas con el método Movitransfer: "Lo puedo aplicar en cualquier circunstancia de la vida, ya sea en lo cotidiano o en el deporte que practico" (informante 12).

Mediante las clases de Movitransfer, se enriquece el repertorio motor de las personas, pues son capaces de redescubrir posibilidades motrices que ya no utilizaban o tenían olvidadas, y debido a ello se convierten en personas mucho más hábiles, eficaces y conscientes de sí mismas, por lo que tanto sus prestaciones deportivas como su desempeño cotidiano mejoran de manera ostensible con el paso del tiempo.

Puede afirmarse que la práctica sistemática del método de educación física Movitransfer genera grandes cambios en la vida de las personas. Se trata de un proceso gradual, sistemático y de riqueza ilimitada que transforma a las personas desde dentro permitiéndoles expresarse con todo lo que tienen, con sus bloqueos, sus miedos, sus impulsos y sus sensaciones más íntimas; es dicho proceso de redescubrimiento de las propias competencias motrices lo que provoca un cambio generalizado en todos los aspectos de sus vidas.

\section{La persona y la percepción del propio cuerpo}

La percepción del cuerpo es la base de todo el proceso para iniciar el camino de optimización de las conductas motrices. Este principio hace hincapié en la idea de que las personas, como seres conscientes, pueden percibir paso a paso todas las partes de su cuerpo, su colocación, su peso, sus sensaciones, sus estados de ánimo y, sobre todo, sus necesidades. Se trata de sentir el cuerpo a través de la emoción, de percibir cómo se encuentran sus partes, así como su totalidad: "Aprendí a percibir partes de mi cuerpo con más exactitud" (informante 5). "Percibiendo mi cuerpo pude interpretar las necesidades que tenía" (informante 10).

Es decir, el método consiste no solo en focalizar la atención plena en cada una de las diferentes partes de la realidad corpórea y sensitiva, sino también, en comenzar a escuchar las necesidades del propio cuerpo: si necesita estirarse, contraerse, relajarse, sentir los apoyos en el suelo, desplazar las muñecas en diferentes direcciones o, simplemente, bostezar y sentirse en completa quietud, como fase preliminar y de puesta a punto 
en cada una de las sesiones de Movitransfer. Todas estas percepciones del propio cuerpo, así como los aprendizajes y los descubrimientos que reportan, son descritos de manera clara y contundente: "Aprendí a respirar mejor, pude concentrarme más en mi cuerpo, aprendí a relajar las partes contracturadas de mi cuerpo, ya que puedo detectar mejor donde estoy anudada" (informante 16).

Es posible conectarse con el propio cuerpo desde el presente, el aquí y el ahora, para poder relajarlo, sentir cómo se encuentran sus diferentes partes y de qué manera actuar para aliviar las zonas de mayor tensión: "Aprendí a conocer mi cuerpo, a llevarlo a la experiencia de sentir sus nudos y dolores musculares, podía percibirlos, desanudarlos y trabajarlos hasta sacarlos" (informante 17).

En un nivel más evolucionado, las personas también son capaces de identificar sus estados emocionales, que en el argot cotidiano del gimnasio se asocian a la expresión "el estado del cuerpo en el día de hoy"; es decir, las emociones que las personas viven en el día a día influyen en los diferentes estados anímicos, sensibles y vitales del cuerpo, por lo que este se encuentra de diferentes maneras a lo largo del día y de los días:

La percepción de mi propio cuerpo y el conocimiento del concepto en el día de hoy, hacen que pueda saber qué es lo que necesita mi cuerpo en ese momento y así desanudarme y deshacer todos los nudos y dolores que voy encontrando en $\mathrm{mi}$ cuerpo (informante 7).

Todo este proceso se desencadena al plantear la situación motriz de desanudarse (Lagardera \& Masciano, 2011b) al comienzo de todas las sesiones. Se trata de un concepto y un procedimiento de vital importancia para la aplicación del método Movitransfer. Es un proceso mediante el cual cada persona lleva a cabo un diálogo de reconocimiento y sensibilización con el estado de su propio cuerpo en ese preciso momento del presente, que engloba todas sus facetas: emocional, mental, motriz, sensible, táctil... un proceso de introyección motriz (Lagardera, 2007b) con el que empiezan todas las sesiones.

Se trata de una especie de aterrizaje en el aquí y el ahora, en el que cada persona tiene la oportunidad de evaluar su estado, de manera tanto global como segmentaria, para saber cómo está el cuerpo el día de hoy. Desanudarse es una propuesta pedagógica que conduce de inmediato hacia el descubrimiento y la aceptación de sí mismo, de su realidad como ser único, lo que permite expresarse libremente a partir de lo que es y se siente en ese mismo instante:

Aprendí a percibir los dolores de mi cuerpo cuando algo andaba mal y hasta sentir si estoy cansado o no y qué intensidad de trabajo hacer ese día en particular, ya que aprendemos a detectar el cuerpo del día de hoy, lo llamamos así porque no todos los días estamos de la misma forma por distintas cuestiones externas o internas a nosotros (informante 15).

Afinar la percepción de sí mismo se convierte en un procedimiento de vital importancia para poder dar respuesta a los diferentes estados del cuerpo, y es necesario que cada persona se entrene como observadora de sí misma para poder relacionar sus estados emocionales con sus estados anímicos, mentales y vitales: "Aprendí que el estado de mi cuerpo está muy influenciado por el estado emocional de cada día" (informante 13).

Al experimentar estos procesos a través de la exploración motriz, las personas comienzan a tener un mayor conocimiento de sí mismas y pueden trasladar dichos hallazgos a su día a día. Si se es capaz de percibirse en clase, también puede lograrse durante las tareas cotidianas: "La percepción me ayudó mucho en lo postural durante el trabajo, ya sea sentado en la oficina o con algún trabajo manual" (informante 8). Esta afirmación alude al trabajo de percibirse en todas las conductas motrices que se realizan a diario, tanto para mejorar la calidad de vida como para ser personas más conscientes de su propio cuerpo y del repertorio motor del que disponen; seres libres que disfrutan profundamente de su motricidad de origen, la que les proporcionó la vida y tenían olvidado en algún rincón de su memoria: "Mediante la concentración y la percepción de todo el cuerpo junto con las emociones, generan una sensación de libertad desde donde siento que no hay límite" (informante 20). Es decir, al ser conscientes de que se expresan a través de sus conductas motrices, tienen una sensación de libertad y de descarga que es indudablemente real, y es a partir de la percepción de su propio cuerpo como logran avanzar en el conocimiento de sí mismos. 
La conducta motriz: pilar básico del método Movitransfer

La conducta motriz es la manifestación unitaria del ser que responde a toda su complejidad, su diversidad y su singularidad (Parlebas, 2001); por esto, Movitransfer aplica su pedagogía teniendo en cuenta esta realidad única e indivisible de toda persona, tanto en lo emocional como en lo motriz o en lo social. Esta concepción supone mucho más que un mero soporte teórico, ya que sus consecuencias en la práctica cotidiana de las clases cambian radicalmente el rumbo de la educación física conocida hasta el momento, lo que permite entender a cada persona como un ser único e irrepetible que actúa y se comporta según sus particularidades: "En Olimpia podemos relacionarnos con nuestro cuerpo, nuestros sentidos y emociones llegando a trabajar desde otros aspectos, no solo en lo estético" (informante 14). También, las personas tienen muy claro que son una unidad indivisible: "En Olimpia aprendí a entender que cuerpo, mente y emoción son una misma cosa” (informante 11).

Conectarse con el interior de la persona a través de la motricidad singular de cada cual, de su conducta motriz, es, en definitiva, una característica fundamental de Movitransfer, lo que les permite a los participantes identificarse con su realidad inmediata, ser ellos mismos y comenzar a evolucionar desde ese momento y desde ese punto: "Es el método lo que deja salir el toque característico de cada persona, la personalidad de cada uno queda expuesta al instante" (informante 18). Ello no significa otra cosa sino la conducta motriz; es decir, las características particulares con las que cada persona lleva a cabo cada una de las acciones motrices que requieren las situaciones pedagógicas planteadas y propuestas en clase, el toque personal y singular que le es propio a cada participante.

Movitransfer logra aplicar la pedagogía de las conductas motrices de un modo inmediato, en el mismo instante en que se lleva a cabo en clase el desenlace motor, aprovechando espacios y momentos de reflexión compartida (Masciano \& Lagardera, 2011), para que las personas vayan evolucionando hasta ser capaces de autoevaluar sus propias conductas motrices siendo conscientes de sus logros: "Aprendí a no chocarme con mis compañeros, a rodar en diferentes direcciones, a saltar y repiquetear sintiendo el ruido de mis zapatillas como una música de fondo, a girar al pararme" (informante 20), pues aunque los testimonios no hagan referencia explícita a la conducta motriz, estas pueden identificarse fácilmente con cada una de las acciones descritas: "Aprendí a rodar, a deslizarme, a sentarme, a arrodillarme, a pararme, todo de modo fluido y eficaz. Aprendí a encontrar los espacios libres en cualquier tipo de actividad..." (informante 3). Es decir, las personas aprenden a identificar y a evaluar sus conductas motrices según los requerimientos de las situaciones motrices propuestas, y esto es de vital importancia en la vida misma: puede, incluso, prevenir lesiones o situaciones de riesgo en lo cotidiano si las personas aplican lo que han ido descubriendo y optimizando en el gimnasio: "Aprendí a equilibrarme, ante una caída no me lesiono y aprendí a preparar el cuerpo para rodar, para posicionarlo" (informante 21).

El alumnado experimenta una suerte de reconciliación con su propio cuerpo y con su motricidad de origen, comienza a reconocer la colocación de sus partes y a tener conciencia del cuerpo como unidad. Aparece en este punto el concepto de globalidad, unido íntimamente al de conducta motriz, pues a ella hace referencia, dado que es la expresión simple de un complejo proceso, representa su fase inicial, básica para entenderlo y potenciarlo, ya que los participantes de Movitransfer comienzan a entender la globalidad como la base funcional en el desarrollo de cualquier conducta motriz (Masciano \& Lagardera, 2012). Cualquier parte del cuerpo puede tener sentido por sí misma, pero, sobre todo, lo adquiere al formar parte de una globalidad mucho más compleja y completa: "Aprendí que los brazos me sirven para equilibrarme, pero también para girar, para levantarme, para saltar ayudando a impulsarme. Estaba aprendiendo desde cero como un niño a usar mi cuerpo como nuevo" (informante 22).

El concepto de globalidad aplicado de un modo experiencial influye directamente sobre la evolución y la optimización de las conductas motrices. Cualquier persona capaz de comprender y aplicar la globalidad con la que actúa cuantas veces lleva a cabo una conducta motriz, está en el proceso de aprender a evaluarla y optimizarla, lo que equivale de inmediato a mejorar su eficacia y su rendimiento en todas las situaciones motrices de la vida, incluyendo también los deportes:

Es importante también que realicemos un trabajo global del cuerpo, esto hace la diferencia entre poner una pelotita de tenis sobre la línea de la cancha o tirarla fuera de la misma ya que los movimientos 
se realizan con todas las partes del cuerpo, es decir, son una sucesión de ellos (informante 29).

Este modo de obrar desde la globalidad, tan bien explicado por uno de los participantes directos de las sesiones, es la conducta motriz con la que cada persona se adapta, se expresa y lleva a cabo sus prestaciones motrices desde una singularidad única, lo cual convierte a Movitransfer en un método que propone una educación física para toda la vida, que trabaja teniendo en cuenta el desarrollo y la evolución personal, sin importar si son deportistas, amas de casas, abuelos o niños. Un método de educación física para todo el mundo, sin importar edades, género o condición física.

Movitransfer utiliza y aplica el concepto de globalidad como la llave maestra para optimizar las conductas motrices, y así refuerza la idea de que en todas las acciones motrices cotidianas es todo el cuerpo el que actúa en su conjunto.

Esta es una de las premisas del método, pues incluso en un remate de fútbol es la colocación de la muñeca lo que puede orientar adecuadamente la dirección del remate a gol; ello es de capital importancia para el rendimiento óptimo de cualquier futbolista, en este caso, o para el de cualquier otro deportista, independientemente de sus condiciones innatas, dado que al interiorizar con la práctica el concepto de globalidad, siempre se actúa en la optimización de las conductas motrices.

Este y otros ejemplos se utilizan con fines didácticos para que las personas comprendan el concepto y lo apliquen en las ejercitaciones y las situaciones motrices propuestas en clase.

\section{Movitransfer, una filosofía de vida}

Puede decirse que Movitransfer es algo más que una actividad gimnástica o un método de educación física, pues muchos de sus participantes citan al método como un suceso fundamental en sus vidas; es decir, algo que forma parte de sus días y les aporta el equilibrio o el estímulo fundamental para llevar adelante el día a día: "Siento a Movitransfer una parte fundamental en mi vida, lo práctico desde hace unos 17 años" (informante 24). Para las personas que practican con el método desde hace muchos años, este ya forma parte de sus historias de vida, de su currículum personal: "Movitransfer es lo mejor que me pudo pasar en estos últimos 24 años" (informante 27). Se trata de un método que, optimizando las conductas motrices, logra una mejora sustancial de la calidad de vida de las personas practicantes, de modo que explorando y utilizando la motricidad de origen, o, mejor, redescubriéndola (Masciano., 2013), se produce una evolución de las conductas motrices que rebasa con mucho el ámbito de la motricidad humana potenciando y mejorando otros aspectos de la vida, bien sea el rendimiento físico, la mejora estética, la vitalidad cotidiana o un excelente estado de ánimo. De ahí que muchas de las personas practicantes consideren que Movitransfer es un talismán en sus vidas: "Al poco tiempo de haber empezado me di cuenta que es el lugar en donde me quiero quedar, me voy a quedar haciendo actividad física hasta..., tal vez hasta siempre" (informante 19).

Sus más fieles practicantes no toman el método como una moda o una novedad, pues para nada tiene que ver con recursos tecnológicos o sofisticadas máquinas de última generación para ser aplicadas en el deporte y la actividad física, de las que tanto abundan, sino que lo consideran algo de gran interés que le aporta al interior de la persona sensaciones muy profundas, a partir de las cuales logran una conexión íntima y clara consigo mismas, y de tal dimensión que el encuentro semanal en el gimnasio se convierte en un lugar de transformación personal, y así se produce un cambio que estimula la vitalidad, la autoestima y el placer, por ese momento tan especial de la clase que se prolonga mucho más allá en el espacio y el tiempo: "Movitransfer cambió mi vida al transferirme más energía y vitalidad día tras día, es un sistema que nos transforma los sentidos inyectándonos una cuota de optimismo, logrando poner mi mente en blanco después de esa jornada agotadora" (informante 28). Con Movitransfer, la calidad de vida en general mejora de manera ostensible:

A nivel general siento que son todos los ámbitos de mi vida los que han cambiado positivamente desde que concurro al gim, considero un antes y un después del gim, ha sido una gran herramienta para llevar de una manera más amena los problemas de la vida (informante 23).

Es decir, con la práctica asidua es de tal envergadura el cambio generado, tan profundo y radical, que la vida de las personas se transforma en muchos aspectos: "Es un cambio de actitud no solo motriz, sino también frente a la vida" (informante 1). 
En definitiva, con la práctica sistemática de sesiones de educación física orientadas por el método Movitransfer mejora de tal manera la calidad de vida que este quehacer se convierte en una pieza sustancial de un nuevo estilo de vida, algo que cada persona lleva consigo allá por donde vaya, pues las sensaciones de libertad, de aceptarse a uno mismo, de respetar al compañero por diferente que este sea o de ser auténtico y fiel a sí mismo, se transforman en valores para las personas inspirando una filosofía y un modo particular de afrontar la experiencia de la vida: "Para mi dejó de ser un gimnasio para convertirse hoy en el disparador de un estilo de vida" (informante 30). Sin ninguna duda, la forma como las personas que lo practican toman al método se corresponde con la forma como el método toma a la persona, el centro de su pedagogía, aceptándola y respetándola como principio esencial, alentándola a explorarse motrizmente con libertad absoluta, a sentirse libre para expresarse sin ataduras ni miedos. Por eso, siendo Movitransfer un método concebido para aplicar la pedagogía de las conductas motrices, es entendido y aplicado por sus practicantes como un estilo de vida, como aquel espacio y tiempo del Gimnasio Olimpia que cada persona utiliza para expresarse y sentirse tal cual es, completamente libre de poder cambiar su realidad cotidiana a partir de lo que es su ser auténtico: "Podemos hacer del método Movitransfer un modo de vida y llevarlo a cualquier lugar donde estemos" (informante 25).

Los principios del método aplicados en las clases alientan a cada una de las personas asistentes a ser fieles a sí mismas, y así constituyen un estímulo constante para que cada cual sea capaz de optimizar sus conductas motrices según sus posibilidades cotidianas, en la certeza de que esta transformación implica a todas las dimensiones del ser humano actuando como un motor que alimenta la vida de sus participantes. No en vano, en clase cada persona se expresa desde su motricidad, con todo lo que es, sin miedos ni prejuicios, trabajando siempre desde lo que posee y sin copiar ni imitar a nadie; este punto es lo que le confiere seguridad, pues dispone de ese espacio donde nadie le juzga por ser como es; y no solo eso, sino que se le anima a seguir buscando en su interior para hallar la mejor versión de sí mismo.
Esta forma de hacer y de vivir la educación física genera en la persona un cambio radical, que se traduce en una nueva forma de ver la vida y de afrontar los problemas cotidianos, un nuevo modo de hacer y de estar en el mundo, por lo que el método Movitransfer, al proporcionar un entorno pedagógico en el que las personas se sienten libres y aprenden a ser libres, son capaces de poder serlo también en otros ámbitos de la vida, y el método se transforma en una filosofía basada en el respeto a uno mismo y a la singularidad del resto de las personas.

\section{DISCUSIÓN}

Los resultados expuestos en forma de narración literaria, como corresponde a una investigación cualitativa que se limita al estudio de un caso, ponen de manifiesto, a través de un procedimiento inductivo, que la pregunta formulada abre, mediante las respuestas analizadas, cuatro ejes de conocimiento generado en torno a una realidad pedagógica concreta, que puede transformar por completo la educación física conocida hasta hoy, pues:

a. Las situaciones motrices planteadas en clase se construyen a partir de la vida cotidiana de todas y cada una de las personas participantes, lo que significa convertir al gimnasio en un laboratorio vivo, donde las personas acuden a entrenarse y a experimentar los modos de mejorar sensiblemente su vida (Masciano \& Lagardera, 2011). Con esta perspectiva, el método adquiere una dimensión social de gran relevancia.

b. Es la persona, con su singularidad (edad, género, condición física, experiencia vital...), el centro de atención pedagógico predominante, lo cual significa una ruptura sustancial con lo que se ha venido haciendo a lo largo de los últimos 200 años, pues significa adoptar un nuevo paradigma educativo (Lagardera, 2007a; Parlebas, 2003).

c. La conducta motriz se convierte en la llave pedagógica que ayuda a las personas a transformarse y a optimizarse como seres humanos, no tan solo física o motrizmente, sino emocional, afectiva y socialmente, lo que supone 
una aportación innovadora para la educación física, y, así mismo, revolucionaria para todo el sistema educativo. Este modo de concebir y llevar a la práctica la educación física tiene importantes consecuencias en el desarrollo madurativo de las personas en todas las etapas de la vida.

d. La educación física deja de ser un pasatiempo más o menos divertido o un modo sistemático y ordenado de fomentar hábitos motores en las personas, para convertirse en una filosofía de vida, en una práctica consciente que cambia por completo la vida de las personas, lo mismo si es estudiante, carpintero, policía, arquitecto, deportista de élite o jurista de prestigio (Lagardera \& Masciano, 2014).

Las aportaciones de esta investigación cuestionan muchos de los quehaceres y los procedimientos utilizados en la práctica de la educación física, que sigue anclada en los principios y los conceptos del siglo XIX, que considera a las personas objetos de una producción industrial en cadena. La pedagogía de las conductas motrices supone un salto civilizatorio sin precedentes (Lagardera, 2007a, 2007b; Parlebas, 2003) que esta investigación pone en evidencia como algo posible de llevar a la práctica.

\section{CONCLUSIONES Y PERSPECTIVAS}

Esta investigación muestra lo que ya se viene experimentando en el Gimnasio Olimpia desde hace dos décadas: hay otros modos de impartir educación física teniendo en cuenta las necesidades y las características de cada persona. Es posible personalizar la educación física aplicando eficazmente la pedagogía de las conductas motrices mediante el método Movitransfer.

Es posible llevar a la práctica un nuevo paradigma en educación física: el que tiene a la conducta motriz como objeto central de su acción pedagógica. No se trata de un utópico planteamiento teórico o de un sofisticado proceso investigador, sino de una realidad incontestable, pues la unidad del ser es hoy un paradigma científico plenamente aceptado (Damasio, 2010); por ello, la pedagogía tiene el deber moral de dar satisfacción a esta realidad.
Esta investigación supone un primer paso para divulgar una nueva educación física centrada en la persona, que pueda enriquecerse con otras aportaciones, estudios y experiencias, de modo que las personas dedicadas a la docencia en educación física puedan actuar de manera congruente con las necesidades de las sociedades humanas del siglo XXI.

El estudio de caso mostrado sitúa las conclusiones dentro del marco de un gimnasio privado ubicado en una pequeña población de la provincia de Buenos Aires (Argentina), en el que se acepta a personas de cualquier edad y condición, por lo cual es posible que esta experiencia se desenvuelva con otras características en ámbitos metropolitanos, en los diferentes niveles de la educación formal, en ámbitos recreativos, deportivos o terapéuticos. Esta investigación representa un caso único, pero esperamos que no se trate de un ejemplo exclusivo, sino que pueda ser aplicado con carácter general en un inmediato futuro.

\section{REFERENCIAS}

Álvarez, J. L. \& Jurgenson, G. (2003). Como hacer investigación cualitativa. Fundamentos y metodologías. México: Paidós.

Damasio, A. (2010). Yel cerebro creó al hombre. Barcelona: Destino.

Feldenkrais, M. (1988). Autoconciencia por el movimiento. Ejercicios para el desarrollo personal. Buenos Aires: Paidós.

García Ferrando, M., Ibáñez, J. \& Alvira, F. (1992). El análisis de la realidad social. Métodos y técnicas de investigación. Madrid: Alianza editorial.

Lagardera, F. (2007a). La conducta motriz: un nuevo paradigma para la educación física del siglo XXI. Revista Tándem, 20 (24), 89-105. Barcelona: Graó.

Lagardera, F. (2007b). Ejercicio físico y bienestar. Las prácticas motrices introyectivas en el INEFC de la Universidad de LLeida. Lleida: Edicions de la Universitat de Lleida.

Lagardera, F. \& Lavega, P. (2005). La pedagogía de las conductas motrices. Revista Tándem, 18 (21), 79-101. Barcelona: Graó.

Lagardera, F. \& Masciano, A. (2011a). Por una educación física sostenible para el siglo XXI: La pedagogía de las conductas motrices en el gimnasio Olimpia de Chivilcoy. XIV Seminario Internacional y II Latinoamericano 
en Praxiología Motriz: Educación Física y contextos críticos. Universidad Nacional de La Plata, Argentina.

Lagardera, F. \& Masciano, A. (2011b). Aprendiendo a desanudarse: Una práctica psicomotriz introyectiva de autoconocimiento y autorregulación emocional. XIV Seminario Internacional y II Latinoamericano en Praxiología Motriz: Educación Física y contextos críticos. Universidad Nacional de La Plata, Argentina.

Lagardera, F. \& Masciano, A. (2014). Un rayo de luz en el lado oculto de la educación física. La pedagogía de las conductas motrices en el gimnasio Olimpia de Chivilcoy. RICCAFD, 31 (1), 34-45. Universidad de Málaga, España.

Masciano, A. \& Lagardera, F. (2011). Educación física para la vida cotidiana en el siglo XXI. El método Movitransfer. Motricidad a la vida transferible. Revista digital www.efdeportes.com, 16 (163), 1-16. Buenos Aires, Argentina.
Masciano, A. \& Lagardera, F. (2012). Aplicación de la pedagogía de las conductas motrices mediante el método Movitransfer. Revista Acción motriz, 4 (9), 72-63. Universidad de las Palmas de Gran Canaria, España. www.accionmotriz.com

Masciano, A., Masciano, B. \& Lagardera, F. (2013). La pedagogía de las conductas motrices aplicada eficazmente con el método Movitransfer. $X$ Congreso Argentino y $V$ Latinoamericano de Educación Física y Ciencia. Universidad Nacional de La Plata, Argentina.

Masciano, B. (2013). El método Movitransfer. Tesis inédita de licenciatura. Universidad de Flores, Buenos Aires.

Parlebas, P. (2001). Juegos, deporte y sociedad. Léxico de praxiología motriz. Barcelona: Paidotribo.

Parlebas, P. (2003). Un nuevo paradigma en educación física: los dominios de acción motriz. Congreso FIEP: La Educación Física en Europa y la calidad didáctica de las actividades físico-recreativas. Cáceres, Universidad de Extremadura, España. 